\title{
POSIÇÃO ORIGINAL E EQUILÍBRIO REFLEXIVO EM JOHN RAWLS: O PROBLEMA DA JUSTIFICAÇÃO
}

Denis Coitinho SILVEIRA ${ }^{1}$

- RESUMO: O objetivo deste artigo é estabelecer algumas considerações sobre o papel dos procedimentos de posição original e equilíbrio reflexivo na teoria da justiça como equidade de John Rawls, nas obras A Theory of Justice, Political Liberalism e Justice as Fairness: A Restatement. Eu pretendo mostrar que Rawls faz uso de um modelo coerentista-pragmático de justificação dos princípios de justiça em um âmbito público, que é não-fundacionalista em razão da interconexão entre estes procedimentos.

- PALAVRAS-CHAVE: equilíbrio reflexivo; posição original; coerentismo; não-fundacionalismo.

\section{Situando o problema}

Meu objetivo é realizar uma análise dos procedimentos de equilíbrio reflexivo e posição original utilizados por John Rawls, em A Theory of Justice (TJ), Political Liberalism (PL) e Justice as Fairness (JF), procurando evidenciar suas propriedades justificacionais, isto é, que propiciam uma justificação dos princípios de justiça de uma forma coerentista e não-fundacionalista. Em John Rawls, o equilíbrio reflexivo (reflective equilibrium) tem o papel de instaurar a coerência entre os juízos morais particulares dos agentes e os princípios éticos estabelecidos, no caso, os princípios da justiça, como em um esquema procedimental que orienta regras para a ação moral, de forma que se estabeleça a complementaridade entre a cultura política democráti-

1 Professor adjunto do Departamento de Filosofia e do Programa de Pós-Graduação em Filosofia da Universidade Federal de Pelotas (UFPel-RS). Artigo recebido em 04/2009 e aprovado em 06/2009. 
ca de uma sociedade e o ideal normativo de pessoa e sociedade bem-ordenada (TJ, I, § 4; PL, I, § 1). Já a posição original (original position) funciona como um procedimento deontológico que estabelece os pressupostos filosóficos para a escolha de princípios, sendo estes pressupostos considerados como uma situação inicial de igualdade entre as partes que escolhem os princípios sem poderem recorrer ao conhecimento das situações contingentes, isto é, estando sob o véu da ignorância (TJ, III, § 20-30). A intenção central desta análise objetiva apontar para a proximidade entre estes dois procedimentos e a validade contemporânea da filosofia política de John Rawls com seu modelo deontológico mitigado, no momento em que se pode identificar um procedimento de justificação não-fundacionalista ou dogmático, sem contudo reivindicar um posicionamento subjetivista ou mesmo relativista, indicando uma interconexão entre estes dois procedimentos em um horizonte de justificação pública. Para tanto, parto da análise do papel da categoria da posição original na teoria da justiça de Rawls e, posteriormente, realizo a investigação do método do equilíbrio reflexivo. Por fim, apresento algumas interconexões entre estes dois procedimentos nas considerações finais e sua relevância como alternativa ao problema de justificação dos juízos morais particulares. Especificamente, quero saber se (1) a posição original é um procedimento fundacionalista, por fazer uso de critérios formais, como o véu da ignorância, por exemplo, e (2) se o procedimento do equilíbrio reflexivo é circular, por estabelecer a referência justificacional dos princípios de justiça com base nos juízos morais, sendo os princípios critérios normativos para estes juízos, o que poderia implicar conservadorismo ou relativismo.

\section{Posição original (Original position)}

Além de identificar a posição original enquanto um procedimento heurístico de representação, em que estão especificadas determinadas condições formais para o estabelecimento dos princípios de justiça, penso ser importante observar como se chega até esta ideia. O ponto de partida da teoria da justiça como equidade é a ideia central de uma sociedade como um sistema equitativo de cooperação social (society as fair system of cooperation) entre cidadãos que são pessoas livres e iguais (free and equal persons) em uma sociedade bem-ordenada (well-ordered society). A questão que surge é como estabelecer os termos equitativos de cooperação social, isto é, como determinar o que é justo (correto do ponto de vista público) em uma sociedade. Recusando a fundamentação em uma lei divina ou natural, Rawls propõe um modelo contratualista de justificação, pois os termos equitativos de cooperação provêm de um acordo realizado por aqueles que estão comprometidos em defender suas vantagens recíprocas. Tomando 
como um fato o pluralismo razoável (reasonable pluralism), a solução é construir um critério público objetivo para a estrutura básica da sociedade (basic structure) que possa ser assumido por todos com base em seus juízos morais abrangentes (JF, I, § 6.1: 15).

Mas quais são as condições específicas que validam esse contrato? A ideia é situar as pessoas livres e iguais de forma equitativa, de maneira que elas não tenham uma posição de maior vantagem que outras. Também, deve-se excluir a força, a coerção, o logro e a fraude. O objetivo é encontrar um ponto de vista recíproco com base no qual se possa estabelecer um acordo equitativo entre as pessoas livres e iguais mediante o distanciamento das circunstâncias particulares da estrutura básica existente. Aqui se revela a importância do procedimento da posição original sob o véu da ignorância (veil of ignorance). Na posição original, exclui-se o conhecimento de posições sociais, doutrinas abrangentes, raça, etnia, sexo, dons naturais, isto é, as partes (parties) escolhem sob o véu da ignorância, para assegurar um ponto de vista não egoísta de escolha (JF, I, § 6.2: 15-16). Como o conteúdo do contrato trata dos princípios de justiça para a estrutura básica, na posição original são estabelecidos os termos justos da cooperação entre os cidadãos. Por isso é adotada a expressão justiça como equidade (justice as fairness).

Esse contrato é hipotético e a-histórico, pois a pergunta é pelo que as partes poderiam acordar, e não pelo que acordaram, e, também, não se leva em consideração se esse contrato já foi acordado alguma vez (JF, I, § 6.3: 1617). Assim, pode-se perceber que o papel da posição original é dar oportunidade a um procedimento de representação para os objetivos do esclarecimento público. ${ }^{2}$ Ela é um modelo de nossas convicções sobre as condições equitativas de consenso entre cidadãos livres e iguais e sobre as restrições apropriadas às razões. Dessa forma, os termos do contrato podem ser vistos como equitativos e baseados nas melhores razões, o que gera a oportunidade de um critério formal para fundamentar os princípios de uma concepção política de justiça. Pode-se perceber, então, que a posição original apresentase como um procedimento de representação (device of representation) que formaliza as convicções ponderadas (ou juízos morais ponderados ou refletidos) de pessoas razoáveis com base na descrição das partes como situadas de uma forma simétrica (equitativa) e devendo deliberar baseadas nas restrições apropriadas às razões para estabelecer os princípios de justiça (1 equal liberty; 2.1 - fair equality of opportunites, 2.2 - difference principle) (JF, I, § 6.5: 18).

2 Para Guillarme (1999, p. 107), a posição original caracteriza-se por ser um procedimento deontológico de representação que formula uma visão democrática de relações sociais orientadas pela norma de reciprocidade (reciprocity) (Baynes, 1992, p. 51-61). 
No que concerne ao objetivo deste artigo, quero mostrar como o procedimento da posição original não faz uso apenas de um critério formal de representação, mas utiliza, também, os juízos ponderados (considered judgments) dos indivíduos para a justificação dos princípios, isto é, o procedimento da posição original não pode ser compreendido estando afastado do procedimento do equilíbrio reflexivo. E, se isto estiver correto, mostrarei que a posição original não é fundacionalista, mas um procedimento coerentista de justificação pública. No que segue, procurarei evidenciar esta interpretação.

Uma importante referência à relação entre o método da posição original e o do equilíbrio reflexivo é encontrada em TJ, I, § 4, e nela Rawls procura explicar o papel da posição original como um procedimento para a justificação dos princípios. Em sua exposição, o papel da posição original é dar oportunidade ao "status quo" inicial que garante a equidade dos consensos básicos. E isto circunscreve o conceito de justiça como equidade. O problema central enfrentado é a justificação dos princípios, isto é, mostrar de que forma se pode defender a adoção de determinados princípios de justiça que sejam mais razoáveis que outros (TJ, I, § 4: 16). A aposta feita é que pessoas racionais em uma situação inicial de igualdade (situação equitativa) escolhem determinados princípios de justiça, mais razoáveis do que os encontrados em outras concepções de justiça. É por isso que a justificação resolve-se por meio da deliberação: é necessário definir quais princípios seriam racionalmente aceitos em uma situação inicial contratual. Na posição original, encontra-se o modelo contratualista de justificação, uma vez que são as condições específicas desse "estado de natureza" que determinam a escolha dos princípios (TJ, I, § 4: 16).

Mas como funciona o mecanismo da posição original enquanto procedimento justificatório dos princípios, e qual sua relação com a categoria de equilíbrio reflexivo? Em primeiro lugar, temos que a posição original substitui o "estado de natureza" das teorias tradicionais do contrato social. Isto porque um de seus principais elementos é o véu da ignorância. $O$ véu da ignorância é um mecanismo de controle que possibilita às partes não levar em consideração o conhecimento das contingências para a determinação dos princípios (TJ, I, § 4: 16). A ideia central é impedir que concepções individuais de bem afetem os princípios adotados nessa situação inicial, o que implicaria a universalização de um particular. Rawls aqui é explícito: "Exclui-se o conhecimento destas contingências que estabelecem disparidades entre os homens e permitem, então, que eles sejam guiados por seus preconceitos. Dessa forma, se alcança o véu da ignorância de maneira natural" (TJ, I, § 4: 17). É por isso que a posição original é um procedimento justificacional que pode ser adotado a qualquer momento, bastando para isso argumentar em defesa de princípios de justiça com base nestas res- 
trições. ${ }^{3}$ Em segundo lugar, as partes, na posição original, são iguais, isto é, todos têm os mesmos direitos no processo de escolha dos princípios, podendo propor e apresentar razões, e esta igualdade representa a capacidade humana de possuir uma concepção de bem e um senso de justiça (TJ, I, $\S$ 4: 17). Isso implica que os princípios de justiça são aqueles que pessoas racionais aceitariam em condições de igualdade, sendo estas pessoas preocupadas em promover seus interesses particulares. Há, contudo, que se levar em consideração, para a justificação, se os princípios de justiça são coerentes com os juízos morais comuns das pessoas. Chega-se assim ao terceiro elemento da posição original, isto é, ao equilíbrio reflexivo. ${ }^{4}$

O procedimento do equilíbrio reflexivo propõe que se parta de juízos morais concordantes, como o repúdio à escravidão e a tolerância religiosa, para ver se estes juízos são coerentes com os princípios de justiça no que tange à defesa da igualdade e liberdade e, dessa forma, utilizar os princípios de justiça como uma referência normativa ao desacordo moral, a exemplo do que se dá no dissenso sobre a distribuição de riqueza e autoridade. Rawls afirma que estas concepções morais são pontos fixos provisórios que servem de referência para uma concepção de justiça (TJ, I, § 4: 17-18). Por isso, o equilíbrio reflexivo é um procedimento coerentista entre juízos e princípios morais: "Ele é um equilíbrio porque finalmente nossos princípios e juízos coincidem; e ele é reflexivo porque sabemos com quais princípios nossos julgamentos se conformam e as premissas de sua derivação" (TJ, I, § 4: 18). O equilíbrio reflexivo significa um estado de coisas em que é possível perceber avanços e recuos, pois em alguns casos é necessário alterar as condições iniciais do contrato, outras vezes é imperativa a modificação dos juízos morais para acordarem com os princípios. Este equilíbrio possibilita a melhor configuração da situação inicial equitativa, pois (a) expressa pressuposições razoáveis e (b) produz princípios que combinam com os juízos morais comuns. Note-se que é um procedimento coerentista que visa a justificação com base nessa correspondência entre os juízos e os princípios morais no interior da posição original.

3 O não-conhecimento das doutrinas abrangentes caracteriza um véu da ignorância espesso (thick), que implica o consenso sobreposto entre doutrinas abrangentes razoáveis. O véu da ignorância expressa uma característica do construtivismo político, bem como do construtivismo moral kantiano, que é a distinção entre o razoável e o racional, defendendo a prioridade do razoável por ser uma disposição para julgar com base no critério de reciprocidade e aceitar os limites dos juízos. Ver PL, I, § 4.3: 25.

4 Rawls faz uma distinção importante para melhor compreender o procedimento da posição original, a saber, uma distinção entre (1) as partes (parties) na posição original, (2) os cidadãos (citizens) em uma sociedade bem-ordenada e (3) os indivíduos reais com seus juízos ponderados (refletidos) sobre a justiça. É neste terceiro nível apenas que se situa o procedimento do equilíbrio reflexivo, pois este é um procedimento realizado por indivíduos concretos para verificar se existe coerência entre os juízos ponderados e os princípios da justiça como equidade. Ver PL, I, § 4.6: 28. 
Visto dessa maneira, é importante esclarecer o papel e o alcance da posição original como um procedimento coerentista, e não como um procedimento fundacionalista, em que os princípios seriam simplesmente deduzidos dos pressupostos da situação inicial. A posição original significa uma tentativa de harmonizar em um único sistema os pressupostos filosóficos razoáveis para a determinação dos princípios e os juízos morais comuns sobre a justiça:

Eu não defendo que os princípios de justiça propostos sejam verdades necessárias ou deriváveis dessas verdades. Uma concepção de justiça não pode ser deduzida de premissas autoevidentes ou de condições impostas aos princípios; ao contrário, sua justificação é uma questão de apoio mútuo de várias considerações, do ajuste de todas as partes em uma visão coerente. (TJ, I, § 4: 19)

Dessa forma, a posição original tanto é um recurso de exposição que resume o significado dos postulados para os princípios que se podem aceitar como razoáveis, quanto é um critério intuitivo por sugerir sua própria elaboração. Em TJ, I, § 9, Rawls procura detalhar o conceito de juízos ponderados (considered judgments) em equilíbrio reflexivo ao estabelecer algumas considerações sobre o problema moral. ${ }^{5}$ O problema moral central investigado é saber qual o estatuto normativo dos juízos morais, isto é, se eles podem ser considerados objetivos sem, entretanto, se recorrer a um modelo ético fundacionalista para a justificação última dos juízos e princípios. Rawls toma como ponto de partida a capacidade humana de um senso de justiça, isto é, a capacidade de julgar corretamente (razoavelmente) aquilo que é justo ou injusto. Por isso, pode-se apontar a teoria da justiça como uma descrição de nosso senso de justiça (TJ, I, § 9: 41). Esta teoria, entretanto, duvida da capacidade normativa dos juízos morais em razão dos limites dos juízos, em que, se um juízo moral for verdadeiro, o juízo contraditório será falso, apelando para a necessidade de buscar-se a coerência entre estes juízos e os princípios para alcançar a estabilidade social. ${ }^{6} \mathrm{~A}$ ideia aí defendida consiste em

5 Nessa parte de TJ, Rawls (1999, p. 1-19) segue o ponto de vista geral de seu artigo "Outline of a Decision Procedure for Ethics". Neste artigo, Rawls procura por um procedimento razoável de decisão que seja suficientemente forte (objetivo) para estabelecer um critério de arbítrio dos conflitos do desacordo moral e alcance a estabilidade com base em um método racional de investigação. A ideia era mostrar os princípios implícitos nos juízos ponderados (considered judgments) de juízes competentes (competent judges) com base no seguinte método: (i) seleciona-se uma classe de juízos morais (com base na moralidade de senso comum) e (ii) identifica-se se eles são coerentes com princípios razoáveis e justificáveis; se existe esta coerência, então, (iii) estes juízos morais são juízos ponderados (refletidos) e servem de critério justificacional para os princípios. Assim, passa-se a contar com princípios razoáveis e justificáveis para arbitrar o dissenso moral.

6 Ao recusar uma teoria semântica tradicional, na qual o significado do dito teria um correspondente ontológico, Rawls apela para um modelo pragmatista, em que o significado dos enunciados morais será determinado em seu uso, isto é, em seu contexto. Os limites dos juízos são abordados em $P L$, II, § 2.3: 56-57. 
estabelecer um procedimento deontológico para a escolha dos princípios, de forma que sirvam de referência normativa aos juízos morais. ${ }^{7}$

Uma questão importante é saber quais juízos morais podem ser levados em consideração e quais devem ser deixados de lado nesse processo. Para tanto, Rawls faz uso do conceito de juízos ponderados: "Juízos ponderados são simplesmente os que são feitos sob condições favoráveis ao exercício do senso de justiça e, portanto, em circunstâncias em que não ocorrem as desculpas e explicações mais comuns para se cometer um erro" (TJ, I, § 9: 42). Dessa forma, os juízos ponderados são aqueles defendidos após uma reflexão cuidadosa com base em princípios, excluindo-se aqueles que surgem em situações de dúvida, medo ou insegurança etc., afirmando o senso de justiça como uma capacidade mental. E, uma vez que se considera o senso de justiça como uma capacidade mental, envolvendo o exercício do pensamento, os juízos pertinentes são aqueles apresentados em condições favoráveis para a deliberação e o julgamento em geral (TJ, I, § 9: 42). Rawls aponta o fato de que há necessidade de explicitar o conceito de equilíbrio reflexivo, porque a justiça como equidade é a hipótese na qual os princípios que seriam escolhidos na posição original são iguais aos que correspondem aos juízos ponderados dos indivíduos, e estes princípios descrevem o senso de justiça (TJ, I, § 9: 42). Isto porque na teoria da justiça os dois princípios de justiça seriam escolhidos na posição original no lugar de outras concepções de justiça, como a do utilitarismo e a do perfeccionismo, e estes princípios se harmonizariam melhor com os juízos ponderados, em contraposição às alternativas citadas (TJ, I, § 9: 43). Como Rawls não assume uma posição intuicionista, realista ou mesmo naturalista, ele não faz uso da categoria de fato moral, que seria tomado como ponto de partida objetivo para a fundamentação dos princípios. Os juízos ponderados em equilíbrio reflexivo ocupam, entretanto, o lugar de fato moral que serve de orientação aos princípios, sendo a justiça como equidade uma teoria dos sentimentos morais (theory of the moral sentiments) (TJ, I, § 9: 42). A aposta de Rawls para explicar os juízos ponderados em equilíbrio reflexivo é tomá-los como hipóteses contingentes e fatos genéricos, pois uma teoria substantiva de justiça não pode estar baseada apenas em verdades lógicas e definições, já que a análise dos conceitos morais e seu a priori constitui-se como uma base muito frágil. Por mais que Rawls queira distanciar-se do utilitarismo e perfeccionismo, ele acaba por assumir algumas premissas realistas e intuicionistas que complementam seu projeto deontológico kantiano.

7 Este procedimento é similar ao problema de descrição do senso de correção gramatical de frases da língua materna. Rawls estabelece uma analogia entre o uso de princípios morais contidos nos juízos morais cotidianos e a estrutura dos falantes nativos de uma língua, que utilizam as regras gramaticais em sua fala, sem precisamente conhecer essa estrutura de regras gramaticais (TJ, I, § 9: 41). 
Em TJ, III, Rawls analisa o argumento em favor das concepções de justiça, e faz referência ao equilíbrio reflexivo, situando a teoria da justiça como equidade entre as teorias dos sentimentos morais, sentimentos que são manifestados nos juízos ponderados em equilíbrio reflexivo, resolvendo o problema da justificação da seguinte maneira:

Mas a questão da justificação é resolvida, na medida do possível, através da demonstração de que há uma interpretação da posição original que melhor expressa as condições que, de forma geral, se considera razoável impor à escolha dos princípios, mas que, ao mesmo tempo, conduz a uma concepção que caracteriza nossos juízos ponderados em equilíbrio reflexivo. (TJ, III, § 20: 105)

Isso caracteriza a posição original como um procedimento de prova, pois os princípios de justiça distinguem os juízos ponderados, isto é, o senso de justiça, que é tomado intuitivamente como ponto de partida ou como prova indireta da validade dos princípios. Veja-se que neste procedimento há dois elementos interconectados:

(1) Elemento deontológico: situação inicial de igualdade em que as partes escolhem sob o véu da ignorância, partes que são representantes de pessoas racionais e morais;

(2) Elemento teleológico: os princípios de justiça escolhidos caracterizam o senso de justiça, isto é, os juízos ponderados são resultados de uma equilibrada reflexão.

Nota-se que os juízos ponderados são elementos de prova para os princípios porque eles já estão pressupostos nas partes que escolhem na posição original sob o véu da ignorância, isto é, as partes, como representantes filosóficos dos cidadãos, não possuem conhecimento das situações contingentes, mas possuem um senso de justiça e uma concepção de bem, o que implica escolher com base naquilo que promove seus interesses particulares e, também, em escolher com base em juízos morais que expressam um julgamento razoável sobre as questões de justiça básica e elementos constitucionais. ${ }^{8}$ Dessa forma, percebe-se que a justificação dos princípios morais não se encontra em um procedimento de dedução transcendental, em que, dada uma situação formal X, os princípios seriam daí deduzidos, o que representaria defender um modelo fundacionalista de justificação. Como os juízos morais ponderados são utilizados como pressupostos na escolha dos

8 Rawls enfatiza que o procedimento do equilíbrio reflexivo apela para a coerência entre os juízos ponderados (refletidos) contidos na cultura pública da sociedade, como se vê no repúdio à escravidão e na tolerância religiosa, e os princípios morais públicos que estão implícitos em uma concepção política razoável de justiça. Nota-se que o método de justificação dos princípios da justiça como equidade se dá com base na força contratual que as partes possuem ao poderem escolher estes princípios em detrimento de outros princípios de justiça, como o utilitarista, por exemplo. Esta teoria moral da justiça como equidade é justificada, por sua vez, com base nos juízos refletidos concordantes com estes princípios da justiça como equidade. Ver PL, I, § 1: 8. 
princípios e, também, como prova indireta da validade dos princípios, pode-se falar na utilização de um modelo coerentista de justificação, apostando-se em que juízos e princípios morais possam encontrar-se em equilíbrio reflexivo.

Esse posicionamento antifundacionalista fica muito claro em TJ, IV, § 40, em que se analisa a referência kantiana da justiça como equidade. Rawls esclarece que a posição original deve ser compreendida como uma interpretação procedimental da concepção kantiana de autonomia e do imperativo categórico com base na estrutura de uma teoria empírica (TJ, IV, § 40: 226). A ação autônoma se dá quando os princípios são escolhidos por pessoas racionais e morais. O acréscimo rawlsiano está em considerar que (1) os princípios escolhidos devem ser aplicados à estrutura básica da sociedade, e não à vida do indivíduo como um todo e que (2) as premissas que caracterizam essa estrutura são utilizadas para a dedução dos princípios, como, por exemplo, os bens primários (TJ, IV, § 40: 223). Também, os princípios de justiça são considerados da mesma forma que os imperativos categóricos, uma vez que estes princípios são escolhidos na posição original como o do ponto de vista do eu noumênico, em que não é levado em consideração o conhecimento contingente (TJ, IV, § 40: 225). Entretanto, (1) a escolha da pessoa como um eu em si é uma escolha coletiva, e não individualizada e (2) esta escolha não é transcendental, pois as partes levam em consideração as condições da vida humana, isto é, levam em conta os aspectos heterônomos para a escolha dos princípios (TJ, IV, § 40: 226).

\section{Equilíbrio reflexivo (Reflective equilibrium)}

O método do equilíbrio reflexivo caracteriza-se por procurar estabelecer a regra com base no uso, visando a evitar uma reivindicação fundacionalista para os critérios universais. A ideia geral é (i) partir dos juízos morais concordantes em uma sociedade democrática, pela tolerância religiosa e o repúdio à escravidão, por exemplo, para identificar a coerência com os princípios de liberdade e igualdade, a fim de (ii) usar os princípios da justiça para o estabelecimento de julgamento dos juízos morais discordantes, como sobre estabelecer o critério para a distribuição dos bens, (iii) com base em uma teoria moral-política, como a que vê a justiça como equidade, por exemplo (TJ, I, § 4: 17-18). O objetivo é pensar a teoria da justiça como equidade enquanto uma descrição de nosso senso de justiça, de forma que os princípios escolhidos na posição original correspondam aos juízos ponderados. É um método de justificação em ética procurando opor-se ao intuicionismo racional, que toma como ponto de partida a existência de fatos morais que podem ser intuídos, sem, contudo, defender o posicionamento 
oposto de antirrealismo (relativismo moral), o qual não vê a possibilidade de falar-se em fatos morais independentemente das crenças. ${ }^{9}$ Rawls utiliza o procedimento do equilíbrio reflexivo como núcleo central de sua concepção política de justiça, de forma que se estabeleça uma teoria normativa da escolha pública (política), harmonizando assim os juízos morais particulares com os princípios de justiça. É um processo de justificação de crenças, garantindo a identificação da objetividade dos juízos e princípios morais com base na coerência entre eles, sendo um teste para a validação do senso de justiça compartilhado, estabelecendo-se princípios morais de acordo com uma teoria moral e com as convicções morais refletidas, conformando, além disso, os juízos morais convergentes com base na coerência com os princípios da justiça como equidade. ${ }^{10}$

Pode-se apontar, então, o fato de que o método do equilíbrio reflexivo possui uma abordagem coerentista de justificação em ética devido à expectativa de revisão de crenças particulares em todos os níveis da operação de avanço e recuo, contrastando com modelos fundacionalistas que tomam algum subconjunto de crenças como pontos fixos que não podem ser revisados, isto é, que tomam os princípios ou juízos morais como elementos fundamentais de um enunciado moral que seriam diretamente justificáveis. ${ }^{11}$ Este método foi proposto por Nelson Goodman, sendo uma abordagem para a justificação de regras da lógica indutiva, e defende a idéia de que se podem justificar regras de inferência em lógica indutiva e dedutiva com base

9 Para Guillarme, esse método é um procedimento de justificação de crenças (processus de justificacion de croyances), garantindo a objetividade dos juízos e princípios morais com base em sua Coerência (Guillarme, 1999, p. 13-14; e também Baynes, 1992, p. 70).

10 Segundo Norman Daniels (1996, p. 1-3), o equilíbrio reflexivo é o ponto final de um processo de deliberação em que se refletem e se revisam as crenças individuais sobre uma determinada área de investigação, moral ou não-moral. Este método consiste na operação de avanços e recuos entre os juízos ponderados (ou intuições) sobre casos particulares, os princípios ou regras que se acredita orientá-los e as considerações teóricas que se assume em aceitar estes juízos ponderados ou princípios, revisando qualquer dos elementos quando necessário, a fim de se conseguir uma coerência aceitável entre eles. Alcança-se um equilíbrio reflexivo quando os juízos, princípios e teorias possuírem uma unidade em razão de juntos serem dotados de um maior grau de credibilidade. Por exemplo, um princípio ou juízo sobre um caso particular pode ser justificado quando ele for coerente com o resto das crenças do indivíduo sobre a ação correta e após a devida reflexão sobre as revisões necessárias do sistema de crenças deste indivíduo.

11 David Brink (1989, p. 101-104) estabelece a seguinte distinção entre os modelos coerentista e fundacionalista em ética: o fundacionalismo (fundationalism) moral assegura que uma crença moral $p$ é justificada em caso de $p$ ser igualmente (a) fundamentado (foundational), isto é, autojustificado, e (b) baseado em um tipo de inferência de crenças fundamentadas (foundational). Já o coerentismo moral assegura que uma crença moral $p$ é justificada na medida em que ela seja parte de um sistema coerente de crenças (morais e não-morais), e a coerência em p's explica parcialmente por que se defende $p$. Afirma que o coerentismo moral é essencialmente encontrado no método de equilíbrio reflexivo amplo utilizado por John Rawls (ver também Audi, 1993, p. 49-164). 
em sua coerência com os juízos inferenciais de casos particulares. ${ }^{12}$ Embora a origem do procedimento do equilíbrio reflexivo encontre-se nas discussões sobre a justificação da lógica indutiva, seu principal desenvolvimento ocorreu em ética e filosofia política. Especificamente, o método obteve proeminência, e também o nome pelo qual é conhecido, na esteira da divulgação do uso que lhe foi dado por Rawls em TJ (1971).

$\mathrm{Na}$ justiça como equidade, além de os princípios de justiça serem escolhidos com base nas restrições do véu da ignorância, eles devem corresponder aos juízos ponderados sobre justiça em equilíbrio reflexivo. Se eles não lhes corresponderem, é necessário revisar as restrições na situação contratual até se chegar a um acordo que gere princípios que estejam em equilíbrio reflexivo com os juízos ponderados sobre a justiça. Assim, o dispositivo do contrato deve estar ele próprio em equilíbrio reflexivo com o restante das crenças particulares sobre a justiça. O contrato é um importante instrumento para a construção dos princípios, pois ele auxilia na determinação de quais princípios devem ser escolhidos entre as opiniões divergentes, mas a justificação destes princípios deve derivar do equilíbrio reflexivo entre estes e os juízos ponderados. Esta coerência envolve mais que meramente uma consistência lógica, pois as crenças morais contam para a justificação dos princípios que tenham por base uma teoria moral de fundo. ${ }^{13}$

Em JF, Rawls situa o procedimento do equilíbrio reflexivo como um procedimento de justificação pública (public justification), juntamente com os procedimentos de consenso sobreposto (overlapping consensus) e razão pública (public reason) (JF, I, § 9.1: 26). O papel da ideia de uma justificação pública é compreender a ideia de justificação de forma adequada a uma concepção política de justiça para uma sociedade que se caracteriza pelo pluralismo razoável, como pode ser observado em uma democracia, por exemplo (JF, I, § 9.1: 26). Esta ideia de justificação pública está conectada a outra ideia fundamental da justiça como equidade que é a de uma sociedade bem-ordenada, pois tal sociedade é organizada por uma concepção política de justiça, e isto significa que (1) é uma concepção moral específica para a estrutura básica da sociedade (não para indivíduos e grupos); (2) não é uma doutrina abrangente, sendo apenas uma concepção razoável em que seus princípios expressam valores políticos para esta estrutura básica; (3)

12 A proposta de Goodman (1954, p. 31-58) era encontrar uma referência não-metafísica para as regras com base em uma perspectiva pragmatista, rejeitando a idéia de um fundamento ontológico independente da teoria.

13 Samuel Freeman (2007, p. 42) afirma que a ideia de equilíbrio reflexivo toma como pressupostos as ideias de juízos ponderados e convicções morais, sendo os juízos ponderados os julgamentos morais em que temos grande confiança, como os juízos que afirmam a injustiça da intolerância religiosa e da discriminação racial, por exemplo. Para ele, o método do equilíbrio reflexivo reivindica apenas uma justificação moral no âmbito de um procedimento público de justificação, pois impõe uma condição de publicidade (publicity) para as partes escolherem na posição original. 
está restrita a ideias fundamentais que se encontram na cultura política pública de uma sociedade democrática, como, por exemplo, a ideia de uma sociedade como um sistema equitativo de cooperação social e a ideia de cidadãos como livres e iguais (JF, I, § 9.1: 26-27).

O processo de uma justificação pública significa que os juízos políticos devem ser justificados entre os cidadãos, e isto representa um esforço de convencê-los por meio da razão pública, isto é, mediante raciocínios e inferências adequados a questões políticas básicas, recorrendo apenas a determinados valores políticos que sejam razoáveis aos outros (JF, I, § 9.2: 27). Esta justificação pública depende de um acordo de juízos políticos, pelo menos no que diz respeito aos elementos constitucionais essenciais, a saber: (1) os princípios fundamentais que determinam a estrutura geral do governo e seu processo político; prerrogativas do Legislativo, Executivo e Judiciário; limites da regra da maioria; e (2) direitos e liberdades básicos iguais de cidadania (direito de votar e participar da política, liberdade de pensamento, associação, consciência e garantia do estado de direito) (JF, I, § 9.3: 28). O procedimento de uma justificação pública tem por base tomar como ponto de partida as ideias fundamentais contidas na cultura política para formar uma base pública de justificação, que todos os cidadãos (tomados como racionais e razoáveis) podem endossar apoiados em suas doutrinas abrangentes (concepções filosóficas, religiosas, morais). Dessa maneira, tem-se um consenso sobreposto de doutrinas razoáveis, e isto implica assumir uma concepção política em equilíbrio reflexivo (TJ, I, § 9.4: 29). ${ }^{14}$ Como ela não é uma doutrina abrangente, a teoria da justiça como equidade não necessita mostrar que esses juízos são verdadeiros com base em um intuicionismo racional ou em um racionalismo transcendental, bastando que se alcance o consenso sobreposto em uma concepção política (moral) de justiça que esteja de acordo com os juízos ponderados dos cidadãos, isto é, em equilíbrio reflexivo.

Rawls faz a defesa de que os cidadãos são capazes de razão (teórica e prática) e dotados de senso de justiça. Em condições normais, estas capacidades desenvolvem-se gradualmente e são utilizadas em diversos tipos de juízos de justiça a respeito da estrutura básica da sociedade, bem como de ações cotidianas da vida prática. De todos os juízos políticos de justiça, são selecionados os juízos ponderados, os proferidos quando as condições são familiares ao exercício das faculdades da razão e do senso de justiça, em que se tem a capacidade de realizar um julgamento correto sem ser afetado por influências divergentes (JF, I, § 10.1: 29). Estes juízos ponderados são aqueles que se podem assumir em equilíbrio reflexivo, isto é, que estão

14 Esta concepção política de justiça defende apenas valores públicos de liberdade e igualdade, assumindo um ideal de cidadania democrática e dever de civilidade no âmbito dos elementos constitucionais essenciais e das questões básicas de justiça. Ver PL, IV, § 7: 164-168. 
de acordo com os valores políticos assumidos pela cultura pública da sociedade, como os juízos morais que condenam a escravidão e defendem a tolerância religiosa. Não importa saber se são necessários, mas sim que sejam assumidos com base em uma tradição política que dá oportunidade a um consenso sobreposto, isto é, um assentimento de todos os cidadãos a respeito dos elementos constitucionais essenciais e das questões de justiça básica. A questão central é como se podem considerar esses juízos ponderados (refletidos) de justiça política mais coerentes com os juízos morais abrangentes, tanto os individuais como os das outras pessoas, sem a imposição de uma autoridade política exterior (JF, I, § 10.2: 30). Isto significa que os juízos podem estar em desacordo, e, para tanto, será necessária a revisão de alguns deles para se chegar a um acordo razoável sobre a justiça política.

Para uma melhor compreensão do procedimento do equilíbrio reflexivo, é necessário estabelecer uma diferenciação entre um equilíbrio reflexivo restrito (narrow) e um equilíbrio reflexivo amplo (wide). Um equilíbrio reflexivo restrito (narrow reflective equilibrium) se dá quando uma concepção política de justiça é facilmente aceitável por alguém, bastando para isso apenas uma pequena revisão de seus juízos morais particulares, e assim estabelecer-se uma coerência entre as convicções gerais, os princípios básicos e os juízos particulares, sem que se levem em conta as distintas concepções de justiça (JF, I, § 10.3: 30-31). Já um equilíbrio reflexivo amplo (wide reflective equilibrium) se dá quando há a consideração de outras concepções de justiça e a força dos argumentos que lhe dá sustentação, como a consideração sobre as concepções de justiça da justiça como equidade, do utilitarismo e do perfeccionismo, de forma que, além de as convicções gerais, os princípios fundamentais e os juízos particulares concordarem, levam-se em consideração estas outras concepções de justiça para a escolha dos princípios (JF, I, § 10.3: 31). O método do equilíbrio reflexivo amplo estabelece uma coerência entre o conjunto de crenças de uma pessoa em três níveis, a saber, entre (i) os juízos morais (moral judgments), (ii) os princípios morais (moral principles) e (iii) as teorias de fundo (background theories). Assim, as teorias de fundo (iii) devem mostrar que os princípios morais (ii) são mais razoáveis que outros princípios alternativos, de forma independente dos juízos morais (i). ${ }^{15}$

15 Para Daniels (1996, p. 22), o ponto central de justificação na teoria da justiça como equidade é estabelecido apenas no nível (iii), isto é, na aceitação de uma teoria da justiça que põe à prova as considerações morais particulares e produz uma sociedade bem-ordenada: "Rawls' Archimedean point is fixed only against the acceptability of particular level III theories". Bo Petersson (1998, p. 127) apresenta este método da seguinte forma: "In one respect, WRE (wide reflective equilibrium) is a method for solving moral problems; in another, WRE is a state of affairs, a result that is achieved by such a method - an equilibrium - that justifies a person's beliefs in certain moral ideas (the personal, subjective level, ' $\mathrm{P}$ is justified in believing $\mathrm{X}$ ') or a certain ethical system or theory (the interpersonal or impersonal, objective level, 'belief $\mathrm{X}$ is justified')". 
Com base nessa distinção, é importante observar que a teoria da justiça rawlsiana faz uso do procedimento do equilíbrio reflexivo amplo. Uma vez que os princípios de justiça seriam escolhidos na posição original, eles são iguais aos que correspondem aos juízos ponderados das pessoas, sendo estes princípios escolhidos ao lado de outras concepções de justiça, como a utilitarista ou perfeccionista, por exemplo (TJ, I, § 9: 43). O equilíbrio reflexivo, além de amplo, deve ser pleno (full), uma vez que a mesma concepção pública de justiça é afirmada pelos juízos ponderados de todos em uma sociedade bem-ordenada. ${ }^{16}$ Em uma sociedade bem-ordenada, as pretensões individuais são arbitradas com base em um ponto de vista público, e, além disso, todos reconhecem que esse ponto de vista é afirmado em equilíbrio reflexivo pleno (full reflective equilibrium) (JF, I, § 10.4: 31).

Esse procedimento do equilíbrio reflexivo amplo e pleno é não-fundacionalista porque a justificação pública não é encontrada com base em uma fundamentação feita de juízos particulares ou convicções específicas que poderiam ser considerados como verdadeiros; antes, esta justificação é alcançada com base na coerência entre as convicções gerais e os juízos particulares com os princípios da justiça como equidade, assumindo um ponto de vista público baseado na ideia de uma sociedade bem-ordenada:

Com base no que dissemos acima (em § 10.2), a idéia de justificação em conjunto com o equilíbrio reflexivo pleno [full] é não-fundacionalista desta forma: nenhum tipo específico de juízo ponderado de justiça política ou nível particular de generalidade é pensado como tendo que carregar consigo todo o peso da justificação pública. (JF, I, § 10.4: 31)

Note-se que o objetivo é oferecer uma outra estratégia para a justificação dos princípios. Seu ponto de partida não é tomar os juízos morais como fatos, o que implicaria assumir uma tese intuicionista; também não se trata de considerar os princípios morais como válidos com base em uma justificação apriorística, o que implicaria um fundacionalismo; tampouco defende a posição de que a justificação encontra-se apenas na coerência entre estes juízos e princípios, o que poderia revelar conservadorismo ou relativismo ${ }^{17}$ A questão central deste procedimento é testar a validade dos prin-

16 Rawls estabelece uma distinção entre equilíbrio reflexivo geral (general) e pleno (full): no primeiro caso, a mesma concepção pública de justiça é afirmada pelos juízos ponderados de todos e, no segundo caso, a mesma concepção pública de justiça é afirmada pelos juízos ponderados de todos em uma sociedade bem-ordenada (JF, I, § 10.4: 31).

17 Scanlon (2003, p. 150-153) responde a essa acusação de conservadorismo e relativismo no método do equilíbrio reflexivo rawlsiano afirmando que os juízos ponderados não são fixados, mas estão abertos a constante revisão, e estes juízos ponderados não são limitados pelos juízos particulares daquilo que é correto, o que, também, não implica a aceitação de todos os juízos nem de todos os princípios morais, dando oportunidade à escolha de um critério objetivo para as crenças morais que se contrapõe ao ceticismo. 
cípios fundamentais com base na aceitação que se pode dar aos julgamentos que seriam decorrentes destes princípios. Assim, o problema da fraqueza dos juízos morais particulares (convicções gerais) é eliminado, pois o que vale são os juízos ponderados, isto é, refletidos com base em determinados princípios, como os princípios da justiça como equidade. Este coerentismo não valida ou invalida todos os juízos morais das pessoas, não subsumindo um ponto de vista subjetivista ou relativista, pois busca uma referência cognitivista e objetivista no horizonte de uma justificação política. De outra parte, não busca uma fundamentação última dos princípios; antes, faz uso dos princípios de justiça como critério normativo público para os juízos morais, assegurando para os juízos ponderados (refletidos) uma força justificacional para estes princípios em um âmbito público. Pode-se apontar o fato de que sua novidade consiste em confrontar o desacordo moral baseandose em uma estratégia de escolha sobre qual teoria daria oportunidade a maior sucesso para a garantia da estabilidade social. ${ }^{18}$

A questão que precisa ser respondida é se não há circularidade nesse procedimento do equilíbrio reflexivo como é utilizado na teoria da justiça como equidade. Se os princípios são orientados pela teoria moral e esta o é pelos juízos ponderados, sendo os juízos morais orientados pelos princípios, onde estaria a justificação propriamente dita? Uma tentativa de responder a esta questão está em observar que o equilíbrio reflexivo pleno caracterizase por seu objetivo prático, além de exigir uma reflexão racional e ser antifundacionalista, satisfazendo a necessidade de construir uma base para a justificação pública em questões de justiça política, isto é, de elementos constitucionais essenciais e questões básicas de justiça distributiva:

Na justiça como equidade, o equilíbrio reflexivo pleno é caracterizado pelo seu objetivo prático, por sua reflexão racional e por seu aspecto não-fundacionalista, como descrito acima. Dessa forma, satisfaz a necessidade de uma base de justificação pública em questões de justiça política; uma coerência entre convicções ponderadas em todos os níveis de generalidade e em equilíbrio reflexivo amplo e geral é tudo o que é requerido para o objetivo prático para alcançar um acordo razoável sobre questões de justiça política. (JF, I, § 10.4: 31-32)

18 Concordando com o argumento de Norman Daniels (1996, p. 59-61), desacordos a respeito de teorias são de mais fácil resolução que os desacordos sobre princípios e julgamentos morais. Dessa forma, não é necessário enfrentar o problema epistemológico a respeito da verdade dos juízos ou princípios, pois a argumentação recai sobre a plausibilidade da teoria, o que remete à defesa de uma melhor organização social. Isso significa que (i) os princípios escolhidos na posição original são justificados não porque eles põem à prova as considerações morais relevantes, mas porque a posição original é um instrumento justificacional aceitável; (ii) a posição original é um instrumento justificacional aceitável porque a teoria profunda relevante é aceitável; (iii) a teoria profunda é aceitável porque ela estabelece uma melhor coerência com o resto das crenças em equilíbrio reflexivo amplo. 
O objetivo prático desse procedimento é alcançado quando uma concepção pública de justiça pode ser assumida, tornando os juízos ponderados mais coerentes com os princípios fundamentais da justiça como equidade, o que traz por consequência utilizar o procedimento da posição original sob o véu da ignorância para estabelecer quais princípios públicos seriam os mais aceitáveis, princípios estes que devem ser escolhidos entre outros princípios alternativos de outras teorias morais, dando oportunidade a uma unidade suficiente para a garantia da estabilidade social. A teoria que melhor responder à construção de um ponto de vista público razoável, que pode ser assumido por todos com base em suas doutrinas abrangentes, em consenso sobreposto, tem sua força justificacional assegurada, especialmente no que toca às questões que envolvem os elementos constitucionais essenciais e as questões de justiça distributiva. ${ }^{19}$ Veja-se que, por sua vez, a escolha da melhor teoria encontra sua referência em determinados juízos, juízos refletidos (ponderados), que se harmonizam com os princípios de justiça formulados na justiça como equidade (JF, III, § 40.3: 134). O que está em jogo neste processo de justificação pública do equilíbrio reflexivo é a possibilidade de aceitação dos princípios de justiça como equidade, que tomam por base a ideia de uma sociedade como um sistema equitativo de cooperação social de uma geração a outra, aceitando o conteúdo institucional dos dois princípios, e a ideia de equilíbrio reflexivo envolve a aceitação que se possa dar a estas ideias e princípios que são assumidos (JF, IV, § 41.1: 136) ${ }^{20}$ Dessa forma, não se pode falar em circularidade, pois os princípios são escolhidos em razão do objetivo prático de garantir a estabilidade social, introduzindo um outro elemento para a deliberação e assumindo um procedimento pragmatista de justificação pública.

\section{Considerações finais}

No final de TJ (TJ, IX, § 87), Rawls aponta para algumas considerações importantes a respeito do problema da justificação em ética. Ressalta que a

19 Para Thomas Pogge (2007, p. 170), a concepção de justiça política de Rawls se apresenta como uma teoria com suficiente unidade, coerência e credibilidade para a garantia da estabilidade social.

20 Fred D'Agostino (2007, p. 195-196) identifica o fato de que a teoria da justiça como equidade faz uso de um método de comensurabilidade (commensuration), que possibilita a cidadãos livres e iguais de uma sociedade democrática reconhecer uma base comum de valores para a estrutura básica da sociedade, refutando o utilitarismo e o intuicionismo por sua incomensurabilidade. Isto implica assumir um caráter pragmatista de justificação em razão do estabelecimento dos princípios da associação política como algo que tem uma função social e política, princípios que estão articulados em equilíbrio reflexivo com os juízos ponderados de justiça de uma sociedade democrática. 
teoria da justiça afasta-se de dois modelos éticos paradigmáticos, a saber, o cartesiano, em que se busca encontrar princípios verdadeiros para fundamentar os juízos morais, e o naturalista, que utiliza definições de conceitos morais em termos de conceitos não morais. Para Rawls, estes modelos apresentam sérios problemas. O primeiro está apoiado em uma fundamentação última dos princípios. O segundo comete a falácia naturalista ao orientar os juízos morais com base em juízos descritivos. Os princípios de justiça não são naturais, nem necessariamente verdadeiros. Na justiça como equidade nem as condições para a escolha nem os princípios básicos podem ser considerados como necessários ou definidores da moralidade e, por isso, como responsáveis pelo ônus da prova. Rawls abandona este modelo ético fundacionalista principalmente por perceber que falta uma clara teoria do significado dos enunciados morais, buscando construir uma teoria moral baseada na ideia de coerência entre princípios formais, juízos ponderados e teorias morais. Por isso, a teoria rawlsiana parte da convicção regida pelo senso comum segundo a qual a justiça é a virtude primeira das instituições sociais, estabelecendo uma concepção moral que procura entender e avaliar os sentimentos a respeito da primazia da justiça, articulando esta opinião comum e orientando sua tendência geral, de forma que os princípios que respeitam a igual liberdade e a igualdade equitativa de oportunidades e o princípio da diferença são aqueles que melhor descrevem o senso de justiça das pessoas que possuem uma tradição democrática, pluralista e tolerante em sua cultura pública.

Pode-se perceber que os princípios de justiça, que são formulados com base nas restrições específicas da justiça como equidade, recebem uma justificação indireta dos juízos ponderados dos indivíduos, pois são estes o fundo comum de onde se formula a teoria rawlsiana de justiça. Embora não se encontre neste modelo ético uma fundamentação última, o que asseguraria a verdade destes princípios, pode-se identificar uma base pública de justificação, o que garante um critério objetivo para orientar o desacordo moral de uma sociedade pluralista, que entende como possível um consenso mínimo sobre os elementos constitucionais essenciais e questões de justiça distributiva em razão de sua razoabilidade. Com base na interconexão dos procedimentos da posição original e do equilíbrio reflexivo, a justiça como equidade apresenta-se como um modelo ético plausível e publicamente justificado que assume o coerentismo moral como a melhor forma de alcançar um critério objetivo de correção para as instituições políticas e sociais.

SILVEIRA, Denis Coitinho. Original position and reflexive balance in John Rawls: the problem of justification. Trans/Form/Ação. São Paulo, v.32(1), 2009, p.139-157. 
- ABSTRACT: The aim of this paper is to raise some considerations about the role of the original position and reflective equilibrium procedures in John Rawls's theory of justice as fairness in A Theory of Justice, Political Liberalism and Justice as Fairness: A Restatement. I want to show that Rawls uses a coherentist-pragmatic model of justification of the principles of justice in a public context, which is nonfoundationalist because of the interconnection between these procedures.

- KEYWORDS: reflective equilibrium; original position; coherentism; nonfoundationalism.

\section{Referências bibliográficas}

AUDI, Robert. The Structure of Justification. Cambridge: Cambridge University Press, 1993.

BAYNES, Kenneth. The Normative Grounds of Social Criticism: Kant, Rawls and Habermas. Albany (NY): SUNY Press, 1992.

BRINK, David. Moral Realism and the Foundations of Ethics. Cambridge: Cambridge University Press, 1989.

BROOKS; FREYENHAGEN (Eds.). The Legacy of John Rawls. Londres: Continuum, 2007.

BURG, Wibren van der; WILLIGENBURG, Theo van (Eds.). Reflective Equilibrium: Essays in Honour of Robert Heeger. Dordrecht (PB): Kluwer Academic Publishers, 1998.

D'AGOSTINO, Fred. "The Legacies of John Rawls". In: BROOKS; FREYENHAGEN (Eds.). The Legacy of John Rawls. Londres: Continuum, 2007, p. 195-212.

DANIELS, Norman. Justice and Justification: Reflective Equilibrium in Theory and Practice. Cambridge: Cambridge University Press, 1996.

FREEMAN, Samuel. Rawls: Routledge Philosophers. Londres: Routledge, 2007.

"Rawls on Justification in Moral Philosophy: Reflective Equilibrium". In: FREEMAN. Samuel. Rawls. Londres: Routledge, 2007, p. 29-42.

FREEMAN, Samuel (Ed.). The Cambridge Companion to Rawls. Cambridge: Cambridge University Press, 2003.

GOODMAN, Nelson. Fact, Fiction, and Forecast (1954). 4. ed. Cambridge: Cambridge University Press, 1983.

GUILLARME, Bertrand. Rawls et l'Égalité Democratique. Paris: PUF, 1999.

PETERSSON, Bo. "Wide Reflective Equilibrium and Justification of Moral Theory". In: BURG; WILLIGENBURG (Eds.). Reflective Equilibrium: Essays in Honour of Robert Heeger. Dordrecht (PB): Kluwer, 1998, p. 127-134.

POGGE, Thomas. John Rawls: His Life and Theory of Justice. Oxford: Oxford University Press, 2007.

"On Justification". In: POGGE, Thomas. John Rawls: His Life and Theory of Justice. Oxford: Oxford University Press, 2007, p. 161-177. 
RAWLS, John. Political Liberalism. Nova York: Columbia University Press, 1996.

Collected Papers. Ed. de Samuel Freeman. Cambridge: Harvard University Press, 1999.

"Outline of a Decision Procedure for Ethics". In: Collected Papers. Ed. de Samuel Freeman. Cambridge: Harvard University Press, 1999, p. 1-19.

A Theory of Justice. Cambridge: Harvard University Press, 2000 [edição revisada].

Justice as Fairness: A Restatement. Ed. de Erin Kelly. Cambridge: Harvard University Press, 2001.

SCANLON, T. M. "Rawls on Justification". In: S. FREEMAN (Ed.). The Cambridge Companion to Rawls. Cambridge: Cambridge University Press, 2003, p. 139-167. 